\title{
WEAK AND STRONG CONVERGENCE TO FIXED POINTS OF ASYMPTOTICALLY NONEXPANSIVE MAPPINGS
}

\section{J. SCHU}

\begin{abstract}
Let $T$ be an asymptotically nonexpansive self-mapping of a closed bounded and convex subset of a uniformly convex Banach space which satisfies Opial's condition. It is shown that, under certain assumptions, the sequence given by $x_{n+1}=\alpha_{n} T^{n}\left(x_{n}\right)+\left(1-\alpha_{n}\right) x_{n}$ converges weakly to some fixed point of $T$. In arbitrary uniformly convex Banach spaces similar results are obtained concerning the strong convergence of $\left(x_{n}\right)$ to a fixed point of $T$, provided $T$ possesses a compact iterate or satisfies a Frum-Ketkov condition of the fourth kind.
\end{abstract}

\section{INTRODUCTION}

In 1972, K. Goebel and W.A. Kirk [2] introduced the class of asymptotically nonexpansive mappings and proved that every asymptotically nonexpansive self-mapping of a nonempty closed bounded and convex subset of a uniformly convex Banach space has a fixed point. After this, several authors have been concerned with the iterative construction of a fixed point of an asymptotically nonexpansive mapping $T$ as the weak limit of the sequence $\left(T^{n} x\right)_{n \in N}$ of iterates, assuming that $T$ is (weakly) asymptotically regular (see for example $[1,3,4,6]$ ).

Let $E$ be a uniformly convex Banach space satisfying Opial's condition, $\emptyset \neq A \subset E$ closed bounded and convex and $T: A \rightarrow A$ asymptotically nonexpansive. Using a demiclosedness result of $\mathrm{J}$. Górnicki [3], we shall show that, under certain conditions, the modified Mann-iteration process $x_{n+1}=\alpha_{n} T^{n}\left(x_{n}\right)+\left(1-\alpha_{n}\right) x_{n}$ converges weakly to some fixed point of $T$. We emphasise that no asymptotic regularity condition is posed on $T$. This result, together with two further theorems concerning the strong convergence of $\left(x_{n}\right)$ to some fixed point of $T$, are given in section 2, while section 1 contains several lemmas needed in the sequel.

Preliminaries. A normed space $(E,\|\cdot\|)$ is called uniformly convex if for each $\varepsilon>0$ there is a $\delta>0$ such that if $x, y \in E$ with $\|x\|,\|y\| \leqslant 1$ and $\|x-y\| \geqslant \varepsilon$ it follows that $\|x+y\| \leq 2(1-\delta)$. $(E,\|\cdot\|)$ is said to satisfy Opial's condition if for each sequence

Received 19th March, 1990.

Thanks are due to Professor J. Reinermann for his interest in this paper.

Copyright Clearance Centre, Inc. Serial-fee code: 0004-9729/91 \$A2.00+0.00. 
$\left(x_{n}\right) \in E^{N}$ weakly converging to a point $x \in E$ and for all $y \in E$ it follows from $y \neq x$ that $\liminf \left\|x_{n}-x\right\|<\liminf \left\|x_{n}-y\right\|$.

Let $A$ be a subset of $E,\left(k_{n}\right) \in[1, \infty)^{\mathrm{N}}$ and $L>0$. A mapping $T: A \rightarrow A$ is called asymptotically nonexpansive with sequence $\left(k_{n}\right)$ if $\lim \left(k_{n}\right)=1$ and $\left\|T^{n} x-T^{n} y\right\| \leqslant$ $k_{n}\|x-y\|$ for all $n \in N$ and all $x, y \in A . T$ is called uniformly L-Lipschitzian if $\left\|T^{n} x-T^{n} y\right\| \leqslant L\|x-y\|$ for all $n \in N$ and all $x, y \in A$, and $T$ is said to be compact if it maps bounded sets into relatively compact ones. Furthermore, a mapping $F: A \rightarrow E$ is said to be demiclosed with respect to $y \in E$ if for each sequence $\left(x_{n}\right) \in A^{N}$ and each $x \in E$ it follows from $\left(x_{n}\right)-x$ and $\lim F\left(x_{n}\right)=y$ that $x \in A$ and $F(x)=y$. For abbreviation we denote the fixed point set of $T$ by $F i x(T)$ and the diameter of $A$ by $\operatorname{diam}(A)$.

Finally, a sequence $\left(\alpha_{n}\right) \in[0,1]^{N}$ is said to be bounded away if $\varepsilon \leqslant \alpha_{n} \leqslant 1-\varepsilon$ for all $n \in N$ and some $\varepsilon>0$.

In what follows we shall deal with the iteration process

$$
x_{n+1}=\alpha_{n} T^{n}\left(x_{n}\right)+\left(1-\alpha_{n}\right) x_{n} .
$$

\section{Auxiliary Results}

Lemma 1.1. Let $(E,\|\cdot\|)$ be a normed space, $\emptyset \neq A \subset E$ convex and $T: A \rightarrow A$ asymptotically nonexpansive with sequence $\left(k_{n}\right) \in[1, \infty)^{N}$ for which $\prod_{\nu=1}^{\infty} k_{\nu}$ converges. For $n \in N$ set $c_{n}=\prod_{\nu=n}^{\infty} k_{\nu}$. Suppose that $x_{1} \in A,\left(\alpha_{n}\right) \in[0,1]^{N}$ and that $\left(x_{n}\right)$ is given by $(M)$. Then

$$
\begin{aligned}
\left\|x_{n+1}-x\right\| \leqslant k_{n}\left\|x_{n}-x\right\| & \text { for all } x \in F i x(T) \text { and all } n \in N \\
\left\|x_{n+m}-x\right\| \leqslant c_{n}\left\|x_{n}-x\right\| & \text { for all } x \in F i x(T) \text { and all } n, m \in N
\end{aligned}
$$

Proof: For $x \in F i x(T)$ and $n \in \mathrm{N}$ we have

$$
\begin{aligned}
\left\|x_{n+1}-x\right\| & =\left\|x_{n+1}-\alpha_{n} T^{n} x-\left(1-\alpha_{n}\right) x\right\| \\
& \leqslant \alpha_{n}\left\|T^{n} x_{n}-T^{n} x\right\|+\left(1-\alpha_{n}\right)\left\|x_{n}-x\right\| \\
& \leqslant\left(\alpha_{n} k_{n}+\left(1-\alpha_{n}\right)\right)\left\|x_{n}-x\right\| \leqslant k_{n}\left\|x_{n}-x\right\|,
\end{aligned}
$$

which establishes (1). To show (2), fix $x \in F i x(T)$ and $n, m \in N$. Then, by (1),

$$
\left\|x_{n+m}-x\right\| \leqslant\left(\prod_{\nu=n}^{n+m-1} k_{\nu}\right)\left\|x_{n}-x\right\| \leqslant c_{n}\left\|x_{n}-x\right\| .
$$

The following lemma was motivated by the method of proof of Theorem 1.1 of [ 6 ] (S.K. Samanta). 
Lemma 1.2. Let $(E,\|\cdot\|)$ be a normed space, $\emptyset \neq A \subset E$ bounded and convex and $T: A \rightarrow A$ asymptotically nonexpansive with sequence $\left(k_{n}\right) \in[1, \infty)^{N}$ for which $\sum_{n=1}^{\infty}\left(k_{n}-1\right)<\infty$. Suppose that $x_{1} \in A,\left(\alpha_{n}\right) \in[0,1]^{N}$ and that $\left(x_{n}\right)$ is given by $(M)$. Then $\lim _{n \rightarrow \infty}\left\|x_{n}-x\right\|$ exists for each $x \in F i x(T)$.

Proof: Since $\sum_{n=1}^{\infty}\left(k_{n}-1\right)<\infty$, it follows that $\prod_{\nu=1}^{\infty} k_{\nu}$ converges. Thus, if we set $c_{n}=\prod_{\nu=n}^{\infty} k_{\nu}$ for all $n \in N$, we have $\lim \left(c_{n}\right)=1$. Fix $x \in F i x(T)$ now. Since $A$ is bounded, we may choose $\varphi: N \rightarrow N$ strictly increasing such that $d=\lim \left\|x_{\varphi_{n}}-x\right\|$ exists. Then, for each $\varepsilon>0$, there is an $n_{0} \in N$ such that for all $n \geqslant n_{0}$
(a) $\left(c_{n}-1\right) \operatorname{diam}(A)<\varepsilon$,
(b) $c_{\varphi_{n}}(\varepsilon+d)<2 \varepsilon+d$ and
(c) $\left|\left\|x_{\varphi_{n}}-x\right\|-d\right|<\varepsilon$.

Additionally, for each $q \in N$ there exists some integer $j_{q} \geqslant n_{0}$ such that $\varphi_{j_{q}}>q+\varphi_{n_{0}}$. Thus, for arbitrary $q \in N$, we have $\varphi_{j_{q}}-\left(\varphi_{n_{0}}+q\right) \in N$, and it follows from (c) and Lemma 1.1 that

$$
\begin{aligned}
d-\varepsilon & <\left\|x_{\varphi_{j_{q}}}-x\right\|=\left\|x_{\varphi_{j_{q}}-\left(\varphi_{n_{0}}+q\right)+\left(\varphi_{\left.n_{0}+q\right)}\right.}-x\right\| \leqslant c_{\varphi_{n_{q}+q}}\left\|x_{\varphi_{n_{0}+q}-x}\right\| \\
& \leqslant\left(c_{\varphi_{n_{0}+q}}-1\right)\left\|x_{\varphi_{n_{0}}+q}-x\right\|+\left\|x_{\varphi_{n_{0}}+q}-x\right\|=b_{q},
\end{aligned}
$$

say. Since $\varphi_{n_{0}}+q \geqslant n_{0}$ and $c_{\varphi_{n_{0}}+q} \geqslant 1$, a further application of Lemma 1.1 together with (a), (b) and (c) leads to

$$
\begin{aligned}
b_{q} \leqslant \varepsilon+\left\|x_{\varphi_{n_{0}}+q}-x\right\| & \leqslant \varepsilon+c_{\varphi_{n_{0}}}\left\|x_{\varphi_{n_{0}}}-x\right\| \leqslant \varepsilon+c_{\varphi_{n_{0}}}\left(\left\|x_{\varphi_{n_{0}}}-x\right\|-d \mid+d\right) \\
& \leqslant \varepsilon+c_{\varphi_{n_{0}}}(\varepsilon+d) \leqslant 3 \varepsilon+d .
\end{aligned}
$$

Hence $d-2 \varepsilon \leqslant\left\|x_{\varphi_{n_{0}+q}}-x\right\| \leqslant d+2 \varepsilon$, and so we have shown that $\left|\left\|x_{m}-x\right\|-d\right| \leqslant 2 \varepsilon$ for all $m \geqslant \varphi_{n_{0}}+1$. Thus $\lim _{m \rightarrow \infty}\left\|x_{m}-x\right\|=d$.

Lemma 1.3. (compare [8, p.484]) Let $(E,\|\cdot\|)$ be a uniformly convex Banach space, $0<b<c<1, a \geqslant 0,\left(t_{n}\right) \in[b, c]^{N}$ and $\left(x_{n}\right),\left(y_{n}\right) \in E^{N}$ such that $\limsup \left\|x_{n}\right\| \leqslant a, \lim \sup \left\|y_{n}\right\| \leqslant a$ and $\lim \left\|t_{n} x_{n}+\left(1-t_{n}\right) y_{n}\right\|=a$. Then $\lim \left\|x_{n}-y_{n}\right\|=0$.

Lemma 1.4. (see [7, Lemma 1.2]) Let $(E,\|\cdot\|)$ be a normed space, $\emptyset \neq A \subset E$ convex, $T: A \rightarrow A$ uniformly $L$-Lipschitzian for some $L>0,\left(\alpha_{n}\right) \in[0,1]^{N}$ and $x_{1} \in A$. Suppose that $\left(x_{n}\right)$ is given by $(M)$, and set $c_{n}=\left\|T^{n} x_{n}-x_{n}\right\|$ for all $n \in N$. Then $\left\|x_{n}-T x_{n}\right\| \leqslant c_{n}+c_{n-1} L\left(1+3 L+2 L^{2}\right)$ for all $n \in N$.

Now we are in a position to prove a lemma which, together with Lemma 1.2, is essential for the results of Section 2. 
Lemma 1.5. Let $(E,\|\cdot\|)$ be a uniformly convex Banach space, $\emptyset \neq A \subset E$ closed bounded and convex, $T: A \rightarrow A$ asymptotically nonexpansive with sequence $\left(k_{n}\right) \in[1, \infty)^{N}$ for which $\sum_{n=1}^{\infty}\left(k_{n}-1\right)<\infty$ and $\left(\alpha_{n}\right) \in[0,1]^{N}$ bounded away. Suppose that $x_{1} \in A$ and that $\left(x_{n}\right)$ is given by $(M)$. Then $\lim \left\|x_{n}-T x_{n}\right\|=0$.

Proof: It follows from Theorem 1 of [2] that $T$ has a fixed point $x$ in $A$. Then $d=\lim \left\|x_{n}-x\right\|$ is well-defined by Lemma 1.2 and $\lim \sup \left\|T^{n} x_{n}-x\right\| \leqslant d$ because $\lim \left(k_{n}\right)=1$ and $\left\|T^{n} x_{n}-x\right\|=\left\|T^{n} x_{n}-T^{n} x\right\| \leqslant k_{n}\left\|x_{n}-x\right\|$ for all $n \in N$. Additionally, $\lim \left\|\alpha_{n}\left(T^{n} x_{n}-x\right)+\left(1-\alpha_{n}\right)\left(x_{n}-x\right)\right\|=\lim \left\|x_{n+1}-x\right\|=d$, so that $\lim \left\|T^{n} x_{n}-x_{n}\right\|=0$ by Lemma 1.3. Now, since every asymptotically nonexpansive mapping is also uniformly $L$-Lipschitzian for some $L>0$, it follows from Lemma 1.4 that $\lim \left\|T x_{n}-x_{n}\right\|=0$.

Note that the above property $" \lim \left\|T^{n} x_{n}-x_{n}\right\|=0$ " is a kind of asymptotic regularity condition. Indeed, denoting $\alpha_{n} T^{n}+\left(1-\alpha_{n}\right)$ id by $S_{n}$, we have $\left\|S_{n} x_{n}-S_{n-1} x_{n-1}\right\|=\left\|x_{n+1}-x_{n}\right\|=\alpha_{n}\left\|T^{n} x_{n}-x_{n}\right\|$ with $\varepsilon \leqslant \alpha_{n} \leqslant 1-\varepsilon$ for some $\varepsilon>0$ independent of $n$. Hence $\lim \left\|T^{n} x_{n}-x_{n}\right\|=0$ if and only if $\lim \left\|S_{n} x_{n}-S_{n-1} x_{n-1}\right\|=0$.

Before we state our main results we need one further lemma which is due to J. Górnicki.

Lemma 1.6. (see [3, Lemma 4]) Let $(E,\|\cdot\|)$ be a uniformly convex Banach space satisfying Opial's condition, $\emptyset \neq A \subset E$ closed and convex and $T: A \rightarrow A$ asymptotically nonexpansive. Then id $-T$ is demiclosed with respect to zero.

\section{MAin Results}

THEOREM 2.1. Let $(E,\|\cdot\|)$ be a uniformly convex Banach space satisfying Opial's condition, $\emptyset \neq A \subset E$ closed bounded and convex and $T: A \rightarrow A$ asymptotically nonexpansive with sequence $\left(k_{n}\right) \in[1, \infty)^{N}$ for which $\sum_{n=1}^{\infty}\left(k_{n}-1\right)<\infty$. Suppose that $x_{1} \in A$ and $\left(\alpha_{n}\right) \in[0,1]^{N}$ is bounded away. Then the sequence $\left(x_{n}\right)$ given by $x_{n+1}=\alpha_{n} T^{n}\left(x_{n}\right)+\left(1-\alpha_{n}\right) x_{n}$ converges weakly to some fixed point of $T$.

Proof: Consider two subsequences $\left(x_{\varphi_{n}}\right)$ and $\left(x_{\psi_{n}}\right)$ of $\left(x_{n}\right)$ which are weakly convergent to some points $x$ and $z$ in $A$, respectively. Since $\lim \left\|x_{n}-T x_{n}\right\|=0$ by Lemma 1.5 and id $-T$ is demiclosed with respect to zero by Lemma 1.6, it follows that $T x=x$ and $T z=z$. Now we are allowed to apply Lemma 1.2 which provides us with the existence of $a=\lim \left\|x_{n}-x\right\|$ and $b=\lim \left\|x_{n}-z\right\|$. Assuming that $x \neq z$ and taking into account the fact that $\left(x_{\varphi_{n}}\right) \rightarrow x$ and $\left(x_{\psi_{n}}\right) \rightarrow z$, it follows from Opial's 
condition that

$$
\begin{aligned}
a & =\liminf \left\|x_{\varphi_{n}}-x\right\|<\liminf \left\|x_{\varphi_{n}}-z\right\|=b \\
& =\liminf \left\|x_{\psi_{n}}-z\right\|<\liminf \left\|x_{\psi_{n}}-x\right\|=a,
\end{aligned}
$$

which is a contradiction. Hence $x=z$.

This, together with the weak compactness of $A$ (note that every uniformly convex Banach space is reflexive), shows that $\left(x_{n}\right)$ possesses exactly one weak cluster point, from which it follows that $\left(x_{n}\right)$ converges weakly to some $y \in A$. Repeating the argument above we see that $T y=y$.

Our next theorem is a generalisation of Theorem 1.5 of [7], where $E$ was assumed to be a Hilbert space.

TheOREM 2.2. Let $(E,\|\cdot\|)$ be a uniformly convex Banach space, $\emptyset \neq A \subset E$ closed bounded and convex, $T: A \rightarrow A$ asymptotically nonexpansive with sequence $\left(k_{n}\right) \in[1, \infty)^{N}$ for which $\sum_{n=1}^{\infty}\left(k_{n}-1\right)<\infty,\left(\alpha_{n}\right) \in[0,1]^{N}$ bounded away and $x_{1} \in A$. Furthermore, suppose that $T^{m}$ is compact for some $m \in N$. Then the sequence $\left(x_{n}\right)$ given by $x_{n+1}=\alpha_{n} T^{n}\left(x_{n}\right)+\left(1-\alpha_{n}\right) x_{n}$ converges strongly to some fixed point of $T$.

Proof: Since $\lim \left\|T x_{n}-x_{n}\right\|=0$ by Lemma 1.5, it follows from the estimation

$$
\begin{aligned}
\left\|T^{m}\left(x_{n}\right)-x_{n}\right\| & \leqslant \sum_{\nu=1}^{m-1}\left\|T^{\nu+1}\left(x_{n}\right)-T^{\nu}\left(x_{n}\right)\right\|+\left\|T x_{n}-x_{n}\right\| \\
& \leqslant\left\|T x_{n}-x_{n}\right\| \sum_{\nu=1}^{m-1} k_{\nu}+\left\|T x_{n}-x_{n}\right\|
\end{aligned}
$$

that $\lim _{n \rightarrow \infty}\left\|T^{m}\left(x_{n}\right)-x_{n}\right\|=0$. Furthermore, as a consequence of the compactness of $T^{m}$, we may choose some subsequence $\left(x_{\varphi_{n}}\right)$ of $\left(x_{n}\right)$ and some $x \in A$ such that $\lim _{n \rightarrow \infty} T^{m}\left(x_{\varphi_{n}}\right)=x$. It follows from the estimation $\left\|x_{\varphi_{n}}-x\right\| \leqslant\left\|x_{\varphi_{n}}-T^{m}\left(x_{\varphi_{n}}\right)\right\|$ $+\left\|T^{m}\left(x_{\varphi_{n}}\right)-x\right\|$, together with the observations above, that $\lim \left(x_{\varphi_{n}}\right)=x$, which in turn implies that $T x=x$, taking into account that $\lim \left\|T x_{n}-x_{n}\right\|=0$. Consequently $a=\lim \left\|x_{n}-x\right\|$ exists by Lemma 1.2. Since $\lim \left(x_{\varphi_{n}}\right)=x$, we conclude that $a=0$.

We close this section with a result analogous to one given by W.V. Petryshyn and T.E. Williamson for (conditionally quasi-) nonexpansive mappings satisfying a FrumKetkov condition of the fourth kind (Theorem 3.3 of [5]).

Lemмa 2.3. (see [5, Lemma 3.1]) Let $(E,\|\cdot\|)$ be a normed space, $\emptyset \neq A \subset E$ closed and convex, $\emptyset \neq K \subset E$ compact and convex, $c \in[0,1)$ and $T: A \rightarrow A$ such that

$$
\operatorname{dist}(T x, K) \leqslant c \operatorname{dist}(x, K) \quad \text { for all } x \in A .
$$


Suppose that $\lambda \in(0,1)$, and define $T_{\lambda}=\lambda T+(1-\lambda)$ id and $c_{\lambda}=\lambda c+(1-\lambda)$. Then

$$
\operatorname{dist}\left(T_{\lambda}(x), K\right) \leqslant c_{\lambda} \operatorname{dist}(x, K) \quad \text { for all } x \in A .
$$

Theorem 2.4. Let $(E,\|\cdot\|)$ be a uniformly convex Banach space, $\emptyset \neq A \subset E$ closed bounded and convex, $T: A \rightarrow A$ asymptotically nonexpansive with sequence $\left(k_{n}\right) \in[1, \infty)^{N}$ for which $\sum_{n=1}^{\infty}\left(k_{n}-1\right)<\infty,\left(\alpha_{n}\right) \in[0,1]^{N}$ bounded away and $x_{1} \in A$. Furthermore, suppose that there exists a nonempty compact and convex subset $K$ of $E$ and some $c \in(0,1)$ such that

$$
\operatorname{dist}(T x, K) \leqslant c \operatorname{dist}(x, K) \text { for all } x \in A .
$$

Then the sequence $\left(x_{n}\right)$ given by $x_{n+1}=\alpha_{n} T^{n}\left(x_{n}\right)+\left(1-\alpha_{n}\right) x_{n}$ converges strongly to some fixed point of $T$.

Proof: For $n \in N$ and $x \in A$ we have $\operatorname{dist}\left(T^{n} x, K\right) \leqslant c^{n} \operatorname{dist}(x, K)$ and, consequently, by Lemma 2.3 ,

$$
\begin{aligned}
\operatorname{dist}\left(\alpha_{n} T^{n} x+\left(1-\alpha_{n}\right) x, K\right) & \leqslant\left(\alpha_{n} c^{n}+\left(1-\alpha_{n}\right)\right) \operatorname{dist}(x, K) \\
& \leqslant\left(c^{n}+1-\varepsilon\right) \operatorname{dist}(x, K)
\end{aligned}
$$

for some $\varepsilon>0$ independent of $n$ and $x$. Since $c \in(0,1)$, there is an $n_{0} \in N$ such that $c^{n}+1-\varepsilon \leqslant 1-\varepsilon / 2$ for all $n \geqslant n_{0}$. Hence, for $n \geqslant n_{0}$, we have $\operatorname{dist}\left(x_{n+1}, K\right)$ $\leqslant(1-\varepsilon / 2) \operatorname{dist}\left(x_{n}, K\right)$ and thus $\operatorname{dist}\left(x_{n+1}, K\right) \leqslant(1-\varepsilon / 2)^{n+1-n_{0}} \operatorname{dist}\left(x_{n_{0}}, K\right)$, from which we conclude that $\lim _{n \rightarrow \infty} \operatorname{dist}\left(x_{n}, K\right)=0$. Since $K$ is compact, this is easily seen to imply that $\left(x_{n}\right)$ possesses some strongly convergent subsequence $\left(x_{\varphi_{n}}\right)$. The rest of the proof is identical to the related part of the proof of Theorem 2.2 .

\section{REFERENCES}

[1] S.C. Bose, 'Weak convergence to the fixed point of an asymptotically nonexpansive map', Proc. Amer. Math. Soc. 68 (1978), 305-308.

[2] K. Goebel and W.A. Kirk, 'A fixed point theorem for asymptotically nonexpansive mappings', Proc. Amer. Math. Soc. 35 (1972), 171-174.

[3] J. Górnicki, 'Weak convergence theorems for asymptotically nonexpansive mappings in uniformly convex Banach spaces', Comment. Math. Univ. Carolin. 30 (1989), 249-252.

[4] G.B. Passty, 'Construction of fixed points for asymptotically nonexpansive mappings', Proc. Amer. Math. Soc. 84 (1982), 212-216.

[5] W.V. Petryshyn and T.E. Williamson, $\mathrm{J}_{\mathbf{r}}$., 'Strong and weak convergence of the sequence of successive approximations for quasi-nonexpansive mappings', J. Math. Anal. Appl. 43 (1973), 459-497. 
[6] S.K. Samanta, 'Fixed point theorems in a Banach space satisfying Opial's condition', $J$. Indian Math. Soc. 45 (1981), 251-258.

[7] J. Schu, 'Iterative construction of fixed points of asymptotically nonexpansive mappings', J. Math. Anal. Appl. (to appear).

[8] E. Zeidler, Nonlinear Functional Analysis and its Applications I, Fized-Point Theorems (Springer-Verlag, New York, Heidelberg, Tokyo, 1986).

\author{
RWTH Aachen \\ Lehrstuhl C für Mathematik \\ Templergraben 55 \\ D-5100 Aachen \\ Federal Republic of Germany
}

